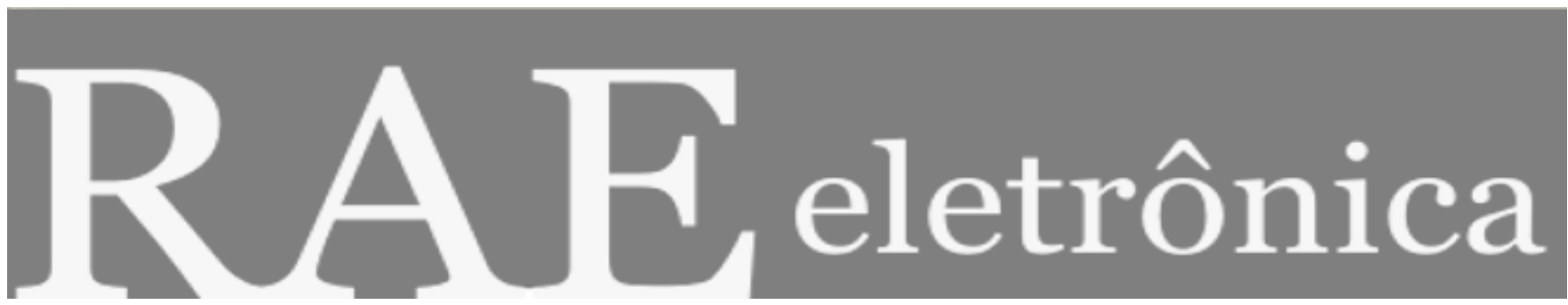

\title{
ABSOLUT: BIOGRAPHY OF A BOTTLE
}

Por

\section{Célia A. S. Marengo Barth}

RAE-eletrônica, Volume 1, Número 1, jan-jun/2002.

http://www.rae.com.br/eletronica/index.cfm?FuseAction=Artigo \&ID=1250\&Secao=RESENHAS\&Volume=1\&Numero=1 $\& A n o=2002$

CCopyright, 2002, RAE-eletrônica. Todos os direitos, inclusive de tradução, são reservados. É permitido citar parte de artigos sem autorização prévia desde que seja identificada a fonte. A reprodução total de artigos é proibida. Os artigos só devem ser usados para uso pessoal e nãocomercial. Em caso de dúvidas, consulte a redação: redacao@,rae.com.br.

A RAE-eletrônica é a revista on-line da FGV-EAESP, totalmente aberta e criada com o objetivo de agilizar a veiculação de trabalhos inéditos. Lançada em janeiro de 2002, com perfil acadêmico, é dedicada a professores, pesquisadores e estudantes. Para mais informações consulte o site www.rae.com.br/eletronica.

RAE-eletrônica

ISSN 1676-5648

(C)2002 Editora: Fundação Getulio Vargas - Escola de Administração

de Empresas de São Paulo.

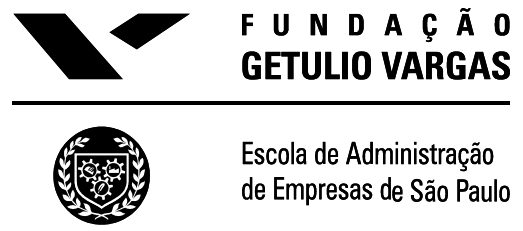




\title{
ABSOLUT: BIOGRAPHY OF A BOTTLE
}

\section{Por Célia A. S. Marengo Barth}

Doutoranda na FGV-EAESP e Mestre em Administração de Empresas pela FGV- EAESP. E-mail:nbarth@uol.com.br

\author{
Absolut: Biography of a Bottle \\ De Carl Hamilton \\ USA: Texere, 2000. 309 p.
}

Uma característica do marketing atual tem sido o enfoque na criação de marcas diferenciadas. Marcas são construídas em torno de atributos e posicionamento do produto, envolvendo nome, embalagem, estratégias de distribuição e propaganda.

A Vodka Absolut teve sua marca consagrada graças ao excelente trabalho das agências de propaganda que desenvolveram uma campanha revolucionária. A Absolut começou como uma marca desconhecida e se tornou uma das 100 marcas mais conhecidas do mundo, graças à qualidade do produto, à sua embalagem única e à sua propaganda, que fizeram com que a vodka ficasse registrada na memória de longo prazo da mente do consumidor.

Depois de ler o livro, o leitor com certeza se sentirá recompensado, quer seja admirador da marca Absolut, quer seja um profissional ou acadêmico de marketing à procura de um interessante caso de construção de marca para análise.

Neste livro, o autor oferece um "estudo de caso histórico": a vodka sueca Absolut e o desenvolvimento de sua garrafa, bem como a sua campanha publicitária nos Estados Unidos.

Pode-se fazer a crítica de que o livro é muito longo para um caso. Por outro lado, a descrição do conceito do produto e da embalagem, os detalhes da campanha com todos os personagens envolvidos e o particular estilo do autor tornam a leitura muito interessante, assemelhando-se a um romance. $\mathrm{O}$ autor não segue uma ordem cronológica, relatando o caso através de flashes baseados em depoimentos, entrevistas e documentos.

Comentando o $20^{\circ}$ aniversário da Vodka Absolut, originária da Suécia, o autor assinala que os suecos obtiveram sucesso na tarefa que parecia impossível: conquistar o grande mercado americano de bebidas com uma nova vodka e com uma campanha que produziu uma revolução na propaganda americana.

Relata-se no livro como três publicitários suecos, liderados por Grunnar Broman, "assaltaram" New York em 1979 com a frase chave: "Senhores, represento uma organização (a Monopoly) que no último ano produziu 147 milhões de litros de pura felicidade humana".

O livro conta que os suecos tinham um relacionamento complicado com o álcool. $\mathrm{O}$ amor antigo dos suecos pela bebida foi sacudido com a reforma do século vinte, através do sistema de regulamentação do álcool. Passaram a existir cotas de álcool para cada cidadão. Entretanto, após a $2^{\mathrm{a}}$ 
Guerra Mundial, foi liberada a venda de álcool, crescendo o número de bêbados. O governo, para reparar a situação, colocou abstêmios no conselho das empresas de bebidas e também no conselho da Liquor Monopoly. A Suécia se tornou o único país do mundo onde abstêmios controlavam a venda de bebida.

A Liquor Monopoly (atual Swedish Wine and Spirits Corporation, produtora da vodka Absolut), fundada na Suécia em 1917, era uma empresa estatal que precisava ser modernizada. A Liquor Monopoly precisava aumentar suas vendas e deveria fazer isto através da exportação.

O autor nos conta que, quando Broman chegou a New York e apresentou sua vodka para a N.W. Ayer, uma agência de publicidade, já tinha previamente preparado 5 temas para a campanha: Vodka da Suécia, Suécia Loira, Vodka da Corte Real, Vodka Pura e, ainda, a idéia de vender uma vodka preta, na realidade uma aquavit. Grunnar Broman desejava uma campanha publicitária absolutamente simples para a vodka.

A agência americana N. W. Ayer precisava de uma conta de bebida, visto que não detinha nenhuma conta deste segmento. Daí a oportunidade de começar a trabalhar com a vodka que os suecos tinham acabado de apresentar.

Depois que o suecos se acertaram com a Ayer, precisava-se achar um importador com urgência. Foi feita uma apresentação aos executivos americanos, em busca de um importador. Um deles criticou a garrafa, sugerindo que seu estilo deveria ser completamente o oposto daquele apresentado pelos suecos (o autor enfatiza várias vezes no livro que a garrafa apresentada pelos suecos era "praticamente invisível").

As agências de propaganda tinham como premissa a idéia de que vender produtos baseando-se somente na força da embalagem e da publicidade é a verdadeira medida do publicitário genial. A vodka não tem cheiro, não tem gosto e não tem cor. A qualidade do produto é difícil de ser rapidamente avaliada pelo consumidor comum. Seria um teste final do agente publicitário. Seria "algo tirado do nada".

Uma grande contribuição para a campanha da Vodka Absolut foi dada por Ernest Dichter, que dizia que as pessoas bebem por razões sociais. As pessoas buscam razões para justificar o álcool. Nesta hora, o rico e o pobre ficam iguais. As pessoas alegam que "estamos buscando uma outra pessoa sem nossos selfs".

Neste ponto do livro, o autor relata que, depois de incansáveis buscas, a Monopoly acaba encontrando um parceiro, a Carrilon, que passa a ser seu importador e distribuidor.

Os altos escalões da Carrilon e da Monopoly costumavam visitar os varejistas pessoalmente, levando sempre uma caneca em uma mão e a vodka na outra. $\mathrm{O}$ autor do livro nos diverte relatando o comentário de um CEO da Carrilon a respeito de uma apresentação de um representante da Monopoly: "Este viking falou tudo em sueco, ninguém compreendeu nada e, no final, com a caneca, todos aprovaram a vodka!".

O argumento utilizado com os varejistas para a venda da vodka sueca era que esta era produzida "segundo as tradições centenárias das destilarias de Ahus, com ingredientes puros, feitos dos melhores 
grãos do país e acondicionados em tonéis de carvalho". A vodka, na realidade, era preparada em Arstadal, ao lado de Estocolmo.

O processo de criação da embalagem “ideal” envolveu várias pessoas. No início, a garrafa idealizada por Grunnar Broman usava a idéia da invisibilidade. Seu sócio Carlsson concebia vários detalhes para o texto da embalagem, acreditando que o segredo residia nesses detalhes. A agência Ayer, participando da campanha da vodka, queria implementar modificações na garrafa antes que esta fosse colocada no mercado. Broman acaba se desligando da Ayer por ter opiniões divergentes quanto à embalagem.O pessoal da Ayer decidiu tirar o $\boldsymbol{e}$ do Absolute.

Posteriormente, a Ayer se fundiu com uma agência que detinha a conta da Bols e, com a fusão, teve que se desfazer da conta da vodka Absolut. Assim, a agência TBWA passou a cuidar da propaganda da Absolut, elaborando 3 campanhas: 1) atacar a vodka Stolichnaya; 2) ressaltar a tradição sueca; 3) usar atributos: Absolut Perfection. Foi aprovada pela Carrilon a idéia da Absolut Perfection.

O principal lançamento da vodka aconteceu no Studio 54, com pessoas do jet set internacional e formadores de opinião. A Absolut passou a fazer parte dos jantares das celebridades e começou a estar presente nos lares americanos.

Em 1985, a Absolut ultrapassou a vodka Stolichnaya e se tornou a número 1 entre as vodkas importadas. Um dos motivos facilitadores foi a invasão russa no Afeganistão (os americanos não aprovaram a invasão). Outro fator foi a excelente campanha publicitária, onde a Absolut era sempre fotografada e pintada (inclusive por Andy Warhol). A publicidade fez com que a Absolut se tornasse parte da cultura americana.

“... Absolut poderia ter sido despretenciosa e não ter emplacado tão fortemente. Agora, muito anos mais tarde e com tantos prêmios, a imagem da garrafa Absolut está embutida em nosso consciente coletivo," comenta um pesonagem do livro.

Concluindo, o autor nos apresenta um livro híbrido de história, negócios, biografia e divulgação, cujo único possível defeito reside na ordenação cronológica um pouco sinuosa. 